\title{
Serum paraoxonase-1 activity as a novel marker in the diagnosis and prognosis of hyperthyroidism
}

\author{
Kale Bhagwat \\ Lecturer, Department of Biochemistry Pandit Deendayal Upadhyay Dental College and Hospital, Kegaon, Dist : Solapur \\ (Maharashtra) \\ *Corresponding author E-mail: kalesachin2644@ rediffmail.com
}

\begin{abstract}
Thyrotoxicosis or hyperthyroidism is the clinical syndrome caused by an excess of circulating free thyroxine and free triiodothyronine, or both. It was first diagnosed in 1979 in the US. Since this time, the frequency of this diagnosis has increased. It is common, affecting about $2 \%$ of women and $0.2 \%$ of men. The most common causes of Thyrotoxicosis are Graves' disease and formation of multinodular goiter and autonomously functioning solitary thyroid nodule. In excessive production of thyroid hormones, the basal metabolic rate can be increased by $100 \%$. Hyperthyroidism also induces a hyperdynamic cardiovascular state that is associated with tachycardia, systolic hypertension, atrial fibrillation and increased cardiovascular mortality. The present study was designed to investigate the relationship among the serum PON 1 activity, lipid profile, and thyroid hormone level in patients with hyperthyroidism. In our research, we have estimated PON 1 activity in hyperthyroidism. We found the PON 1 activity decreased in the hyperthyroid patients $(144.89 \pm 3.27 \mathrm{U} / \mathrm{ml})$ as compared to controls $(214.71 \pm 5.46 \mathrm{U} / \mathrm{ml})$ significantly $(\mathrm{p}<0.05)$. The thyroid hormones $\mathrm{T}_{3}$ and $\mathrm{T}_{4}$ also significantly increase $(\mathrm{p}<0.001)$ in hyperthyroidism. In case of lipid profile triacylglycerol, HDL cholesterol, LDL cholesterol as well as VLDL cholesterol was also found significantly decreased $(\mathrm{p}<0.05)$ in hyperthyroidism. In our study, we found a decrease in triacylglycerol, HDL cholesterol, LDL cholesterol as well as VLDL cholesterol. However, the decrease in HDL, LDL and VLDL cholesterol may also be associated with other disorders. Further, the blood quantity required for lipid profile is large $(5 \mathrm{ml})$ and patients have to be fast for at least 14 hours. Similarly, estimation of lipid profile is time consuming method and hence it is not preferable as a marker.

The increase in thyroid hormones T3 and T4 significantly correlates with hyperthyroidism. However, estimation of thyroid hormone also required large $(5 \mathrm{ml})$ quantity of blood sample. Similarly, the sample required should be always fresh. The estimation is carried generally by enzyme linked immune sorbent assay (ELISA) which is time consuming and costly method. But, on the other hand quantity of blood sample required for estimation of PON 1 activity is very less $(1 \mathrm{ml})$. The estimation of PON 1 activity is easy and the method is chief. The most important thing is that PON 1 activity is decreased only in few disorders. Further, it correlates well with severity of hyperthyroidism. Thus, PON 1 activity is a novel marker in the diagnosis and prognosis of hyperthyroidism.
\end{abstract}

Keywords: paraoxonase - 1, thyrotoxicosis, triiodothyronine, thyroxin, cholesterol.

\section{Introduction}

The thyroid is a gland in the neck that produces two thyroid hormones, thyroxine $\left(\mathrm{T}_{4}\right)$ and triiodothyronine $\left(\mathrm{T}_{3}\right)$. Thyroxine is inactive and is converted by the tissues and organs that need it into tri-iodothyronine. Thyroid hormones from the thyroid gland are necessary for the normal development of body organs. The role of thyroid hormones, put simply, is to regulate the metabolism of virtually all cells in the body. In health, the production of these thyroid hormones is tightly regulated by the secretion of thyroid stimulating hormone (TSH; also known as thyrotropin) from the pituitary gland in the brain. When the thyroid gland becomes affected by disease, sometimes the production or release of thyroxine and tri-iodothyronine can be abnormally high, leading to increased levels in the blood; a state of thyroid overactivity known as hyperthyroidism or thyrotoxicosis [1].

Thyrotoxicosis or hyperthyroidism is the clinical syndrome caused by an excess of circulating free thyroxine and free triiodothyronine, or both. It was first diagnosed in 1979 in the US. Since this time, the frequency of this diagnosis has increased.[2] It is common, affecting about $2 \%$ of women and $0.2 \%$ of men. The most common causes of Thyrotoxicosis are Graves' disease, and formation of multinodular goiter, and autonomously functioning solitary 
thyroid nodule. In excessive production of thyroid hormones, the basal metabolic rate can be increased by 100\%.[3],[4] Hyperthyroidism induces a hyperdynamic cardiovascular state that is associated with tachycardia, systolic hypertension, atrial fibrillation, and increased cardiovascular mortality.[5],[6] Thyroid hormones influence lipid metabolism, including synthesis, mobilization, and degradation.[7] Hyperthyroidism triggers lipolysis in subcutaneous tissue, increasing interstitial glycerol levels, lipid oxidation, and circulating fatty acid concentrations.[8] Paraoxonases are a group of enzymes involved in the hydrolysis of aromatic carboxylic acid esters and organophosphorus insecticides. Paraoxonases (aryl-dialkyl-phosphatase (EC 3.1.8.1) are serum esterases that are synthesized by the liver. There are three known genotypic forms of paraoxonases. They are coded by the PON set of genes as PON 1, PON 2 and PON 3, located on the long arm of chromosome-7. The differences between them lie in their location and activity. PON 1 is synthesized in the liver and transported along with high density lipoproteins in the plasma. It functions as an antioxidant. [9],[10].

PON 1 is a calcium ion dependent esterase which hydrolyses variety of organophosphorus compounds. In the blood PON 1 is closely attached to high-density lipoprotein particles by apolipoprotein $A_{1}$. PON 1 inhibits oxidation of low density lipoproteins and also hydrolysis lipid peroxidation products. This enzyme is also involved in decreasing superoxide ion formation. Thus, it is an important antioxidant enzyme. Its serum concentration is influenced by inflammatory changes and the levels of serum oxidized low density lipoproteins. [11],[12],[13] there have been limited studies about PON 1 levels in hyperthyroidism. The present study was designed to investigate the relationship among the serum PON 1 activity, lipid profile, and thyroid hormone level in patients with hyperthyroidism

\section{Materials and methods}

$5 \mathrm{ml}$ of venous blood were collected in a plain bulb from 30 patients of hyperthyroidism for the study from various hospitals in the solapur city during period Jan - 2010 to Oct - 2012. The sample was collected after the diagnosis of patient for hyperthyroidism in hospital. The blood samples for the controls $(n=30)$ were collected from the healthy volunteers. The obtained blood was centrifuged at $3000 \mathrm{rpm}$ for 15 minutes. The serum were collected and used for assay. The biochemical parameters and methods to be used for their estimations were as follows:

Estimation of paraoxonase 1: Assay of PON 1 is carried out as follow. In an assay tube, $750 \mu$ assay buffer (containing $0.125 \mathrm{M}$ Tris- $\mathrm{HCl}$ and $1.25 \mathrm{M} \mathrm{CaCl}_{2}$ ), $25 \mu \mathrm{l}$ serum and $225 \mu \mathrm{l}$ paraoxon $(6 \mathrm{mM}$ in acetone) is taken. The absorbance was read at $405 \mathrm{~nm}$ on spectrophotometer continuously with a time gap of 1 minute. The enzyme activity was measured by $\mu$ moles of p-nitrophenol formed due to enzymatic reaction in one minute. One unit (U) of enzyme activity is an enzyme activity that liberates one $\mu$ mole of p-nitrophenol in one minute. [14]

Assay of thyroid hormone: The thyroid hormone thyroxine $\left(\mathrm{T}_{4}\right)$ and triiodothyronine $\left(\mathrm{T}_{3}\right)$ are estimated with the help of enzyme linked immune sorbent assay (ELISA).

Estimation of lipid profile: Total and High density lipoprotein (HDL)-cholesterol is determined by cholesterol oxidase -peroxidase method. Triacylglycerol is determined by glycerol-3-oxidase - peroxidase method. Low density lipoprotein (LDL) and Very low density lipoprotein (VLDL) cholesterol are determined from calculation. For estimation of Total and HDL-cholesterol and Triacylglycerol a commercial kit obtained from starchem is used.

\section{Result and discussion}

Hyperthyroidism incidence tends to be higher among older adults, this was explained due to the well-known changes in thyroid gland anatomy and function with aging, and there may be an age-related resistance to thyroid hormone action. [15],[16],[17] Enzyme paraoxonase (PON) was first described in the early 1950's and was introduced as an enzyme having both paraoxonase and arylesterase activity in 1995. The genes encoding the PON family (PON 1, PON 2 and PON 3) are all located on the long arm of chromosome-7.[18],[19],[20] PON 1 and PON 3 are expressed in the liver and after being excreted in the blood, they bind to high-density lipoproteins (HDL); PON 2 is expressed widely in a number of tissues but is not present in the blood. PON 1 play important role in the metabolism of toxic oxidized lipids of both LDL and HDL particles. PON 1, synthesized in the liver and release to the circulation, is available in HDL structure and hydrophobic N-terminal of PON 1 can easily connect to the lipids of HDL. Mackness et al. showed that human PON1 could inhibit LDL oxidation in vitro, prevents formation of oxidized LDL and protects phospholipids in HDL from oxidation by inactivating low density lipoproteins derived oxidized phospholipids.[21],[22],[23].

Serum PON 1 is thought to protect lipoproteins against oxidative modification and is accepted as a pre-atherosclerotic marker. It has crucial roles in protecting LDL against oxidation and detoxification of highly toxic substances. [24]

Thyroid hormones induce the 3-hydroxy-3-methylglutaryl-coenzyme-A (HMG-CoA) reductase, which is the first step in cholesterol biosynthesis. Moreover, triiodothyronine $\left(\mathrm{T}_{3}\right)$ upregulates LDL receptors by controlling the LDL receptor gene activation. This $T_{3}$-mediated gene activation is done by the direct binding of $T_{3}$ to specific thyroid hormone 
responsive elements (TREs). Furthermore, $\mathrm{T}_{3}$ controls the sterol regulatory element-binding protein-2 (SREBP-2), which in turn regulates LDL receptor's gene expression. $\mathrm{T}_{3}$ has also been associated with protecting low density lipoproteins from oxidation.[25],[26].

Thyroid hormones can influence HDL metabolism by increasing cholesteryl ester transfer protein activity, which exchanges cholesteryl esters from $\mathrm{HDL}_{2}$ to the very low density lipoproteins (VLDL) and triacylglycerols to the opposite direction. In addition, thyroid hormones stimulate the lipoprotein lipase, which catabolizes the triacylglycerolrich lipoproteins, and the hepatic lipase, which hydrolyzes $\mathrm{HDL}_{2}$ to $\mathrm{HDL}_{3}$ and contributes to the conversion of intermediate-density lipoproteins to low density lipoproteins and in turn low density lipoproteins to small dense low density lipoproteins. Another effect of $\mathrm{T}_{3}$ is the up-regulation of apolipoprotein-AV, which plays a major role in triacylglycerol regulation. Indeed, increased levels of apolipoprotein-AV have been associated with decreased levels of triacylglycerols. Proposed mechanisms for this effect include the decrease of hepatic VLDL-triacylglycerol production and the increase of plasma lipoprotein lipase levels and activity, resulting in increase of lipoprotein remnant generation due to enhanced lipoprotein lipase-mediated lipolysis of VLDL-triacylglycerol. Moreover, a greater clearance of lipoprotein core remnants, caused by increased hepatic uptake due to an enhanced affinity for the low density lipoproteins receptor, has also been ascribed to apolipoprotein-AV. [27],[28],[29]

The total cholesterol, HDL-cholesterol, LDL-cholesterol, VLDL-cholesterol and triacylglycerol levels were found to be decreased in hyperthyroidism and this may be due to the rapid clearing of chylomicron remnants from blood stimulating cholesteryl ester transfer which in turn stimulate lipoprotein lipase. The main cause of the differences in total cholesterol concentrations is the alterations of LDL-cholesterol levels due to the increase in low density lipoproteins receptor mRNA gene expression, which leads to an increase in activity and number of low density lipoproteins receptors and enhance low density lipoproteins receptor-mediated catabolism of low density lipoproteins particles. This in turn, leads to a decrease in concentrations of LDL-cholesterol and total cholesterol levels. [30],[31],[32]

Furthermore, hyperthyroidism results in enhanced low density lipoproteins oxidability, which is related to FT4 levels. In hyperthyroid a decrease in HDL-cholesterol levels is also observed. This decrease suggested being due to due to increased cholesteryl ester transfer protein mediated transfer of cholesteryl esters from HDL to VLDL and increased hepatic lipase mediated catabolism of $\mathrm{HDL}_{2}$, or due to increased hepatic triglyceride lipase activity.[33],[34]

Through the effects of thyroid hormones, hepatic lipase, a decrease, in $\mathrm{HDL}_{2} / \mathrm{HDL}_{3}$ is reported. The most prominent alteration in HDL-cholesterol is due to the changes in $\mathrm{HDL}_{2}$ subfraction. [35]

In our research, we have estimated PON 1 activity in hyperthyroidism. We found the PON 1 activity decreased in the hyperthyroid patients $(144.89 \pm 3.27 \mathrm{U} / \mathrm{ml})$ as compared to controls $(214.71 \pm 5.46 \mathrm{U} / \mathrm{ml})$ significantly $(\mathrm{p}<0.05)$. (Table $-1)$.

Table 1: Showing comparative values of paraoxonase - 1 activities (Mean \pm SD) in controls and in test (Hyperthyroid patients)

\begin{tabular}{cccc}
\hline Enzyme activity & Control $(\mathrm{N}=30)$ & Hyperthyroid patients $(\mathrm{N}=30)$ & $\mathrm{p}$ value compared to normals \\
\hline PON 1 activity in $(\mathrm{U} / \mathrm{ml})$ & $214.71 \pm 5.46$ & $144.89 \pm 3.27$ & $\mathrm{p}<0.05$ \\
\hline
\end{tabular}

Both the thyroid hormones $\mathrm{T}_{3}$ and $\mathrm{T}_{4}$ also significantly increase $(\mathrm{p}<0.001)$ in hyperthyroidism. We found nearly 4.0 times elevation in $\mathrm{T}_{3}$ level in hyperthyroid patients as compared to controls. While the elevation in $\mathrm{T}_{4}$ level was 2.7 times. (Table - 2)

Table 2: Showing comparative values of thyroid hormones (Mean \pm SD) in healthy controls and in test (Hyperthyroid patients)

\begin{tabular}{lccc}
\hline Biochemical parameters & Control $(\mathrm{N}=30)$ & Hyperthyroid patients $(\mathrm{N}=30)$ & $\mathrm{p}$ value compared to normals \\
\hline Free $\mathrm{T}_{3}$ level in pmol/L & $3.68 \pm 0.94$ & $14.68 \pm 1.13$ & $\mathrm{p}<0.001$ \\
Free $\mathrm{T}_{4}$ level in pmol/L & $15.24 \pm 1.71$ & $41.79 \pm 2.63$ & $\mathrm{p}<0.001$ \\
\hline
\end{tabular}

In case of lipid profile triacylglycerol, HDL cholesterol, LDL cholesterol as well as VLDL cholesterol was also found significantly decreased $(\mathrm{p}<0.05)$ in hyperthyroidism. $($ Table -3$)$

Table 3: Showing comparative values of lipid profile (Mean \pm SD) in healthy controls and in test (Hyperthyroid patients)

\begin{tabular}{cccc}
\hline Biochemical parameters & Control $(\mathrm{N}=30)$ & Hyperthyroid patients $(\mathrm{N}=30)$ & $\mathrm{p}$ value compared to normals \\
\hline Triacylglycerol $(\mathrm{mg} / \mathrm{dl})$ & $146.91 \pm 4.87$ & $122.45 \pm 3.58$ & $\mathrm{p}<0.05$ \\
Total cholesterol $(\mathrm{mg} / \mathrm{dl})$ & $219.63 \pm 5.67$ & $186.38 \pm 3.41$ & $\mathrm{p}<0.05$ \\
HDL cholesterol $(\mathrm{mg} / \mathrm{dl})$ & $57.84 \pm 2.35$ & $43.81 \pm 2.17$ & $\mathrm{p}<0.05$ \\
LDL cholesterol $(\mathrm{mg} / \mathrm{dl})$ & $117.11 \pm 4.21$ & $97.42 \pm 2.86$ & $\mathrm{p}<0.05$ \\
VLDL cholesterol $(\mathrm{mg} / \mathrm{dl})$ & $29.45 \pm 2.74$ & $23.95 \pm 2.48$ & $\mathrm{p}<0.05$ \\
\hline
\end{tabular}

However, decrease in triacylglycerol, HDL cholesterol, LDL cholesterol as well as VLDL cholesterol is non-specific. Also the decrease not correlates with hyperthyroidism. Many times triacylglycerol level never decreases. The decrease in cholesterol derivatives (HDL, LDL and VLDL) may also be associated with other disorders. Further, the blood 
quantity required for lipid profile is large $(5 \mathrm{ml})$ and patients have to be fast for at least 14 hours. Similarly, estimation of lipid profile is time consuming method and hence it is not preferable as a marker.

The increase in thyroid hormones $\mathrm{T}_{3}$ and $\mathrm{T}_{4}$ significantly correlates with hyperthyroidism. However, estimation of thyroid hormone also required large $(5 \mathrm{ml})$ quantity of blood sample. Similarly, the sample required should be always fresh. The estimation is carried generally by enzyme linked immune sorbent assay (ELISA) which is time consuming and costly method.

But, on the other hand quantity of blood sample required for estimation of PON 1 activity is very less (1 ml). The estimation of PON 1 activity is easy and the method is chief. The most important thing is that PON 1 activity is decreased only in few disorders. Further, it correlates well with severity of hyperthyroidism. Thus, PON 1 activity is a novel marker in the diagnosis and prognosis of hyperthyroidism

\section{Conclusion}

The thyroid is a gland in the neck that produces two thyroid hormones, thyroxine $\left(\mathrm{T}_{4}\right)$ and triiodothyronine $\left(\mathrm{T}_{3}\right)$. Thyrotoxicosis or hyperthyroidism is the clinical syndrome caused by an excess of circulating free thyroxine and free triiodothyronine, or both. The present study was designed to investigate the relationship among the serum PON 1 activity, lipid profile, and thyroid hormone level in patients with hyperthyroidism. In our study, we found a decrease in triacylglycerol, HDL cholesterol, LDL cholesterol as well as VLDL cholesterol. However, the decrease in cholesterol derivatives (HDL, LDL and VLDL) may also be associated with other disorders. Further, the blood quantity required for lipid profile is large $(5 \mathrm{ml})$ and patients have to be fast for at least 14 hours. Similarly, estimation of lipid profile is time consuming method and hence it is not preferable as a marker.

The increase in thyroid hormones $\mathrm{T}_{3}$ and $\mathrm{T}_{4}$ significantly correlates with hyperthyroidism. However, estimation of thyroid hormone also required large $(5 \mathrm{ml})$ quantity of blood sample. Similarly, the sample required should be always fresh. The estimation is carried generally by enzyme linked immune sorbent assay (ELISA) which is time consuming and costly method.

But, on the other hand quantity of blood sample required for estimation of PON 1 activity is very less (1 ml). The estimation of PON 1 activity is easy and the method is chief. The most important thing is that PON 1 activity is decreased only in few disorders. Further, it correlates well with severity of hyperthyroidism. Thus, PON 1 activity is a novel marker in the diagnosis and prognosis of hyperthyroidism.

\section{Acknowledgements}

I would like to thank the Biochemistry Department of V. M. Medical College, Solapur. I am also indebted to all the patients and our colleagues for their co-operation in this research.

\section{References}

[1] Kale M.K., Bhusari K.P. and Umathe S.N., Role of thyroid hormones in the generation of widespread oxidative stress, J Cell Tissue Res 2007; 7 (1): 871-6.

[2] Slater M. R., Komkov A., Robinson L. E.,Hightower D. Long-term follow-up of hyperthyroid cats treated with iodine131.Veterinary Radiology and Ultrasound 1994; 35:204-9.

[3] Nicholas A, Nicki R, Brian R. Davidson's Principles \& Practice of Medicine. 20th ed.Edinburgh: Churchill Livingstone, 2006: 746-749.

[4] Desai SP. Clinician's Guide to Laboratory Medinice. 3rd ed. Cleveland: Lexicomp , 2004: 371.

[5] Gago-Dominguez, Castelao J. Role of lipid peroxidation and oxidative stress in the association between thyroid diseases and breast cancer. Crit Rev Oncol Hematol 2008; 68: 107-14.

[6] Fazio S, Palmieri E, Lombardi G. Effects of thyroid hormone on the cardiovascular system. Recent Prog Horm Res 2004; 59: 31-50.

[7] Zhu X and Cheng SY. New insights into regulation of lipid metabolism by thyroid hormone. Current Opin Endocrinol Diabetes Obes 2010; 17: 408-13.

[8] Moller N, Nielsen S, Nyholm B, Porksen N, Alberti KG, Weeke J. Glucose turnover, fuel oxidation and forearm substrate exchange in patients with thyrotoxicosis before and after medical treatment. Clin Endocrinol (Oxf) 1996; 44: 453-9.

[9] S Suleyman et.al. Serum arylesterase and paraoxonase activity in patients with chronic hepatitis.World J Gastroenterol. 11(46); (2005):7351-4.

[10] C Bergmeier, R Siekmeier, W Gross. Distribution spectrum of paraoxonase activity in HDL fractions. Clin. Chem. 50 (12); (2004):2309-15.

[11] H Li, D Liu, C Liang. Paraoxonase gene polymorphisms, oxidative stress, and diseases. J Molecular Medicine. 81 (12); (2003):766-79.

[12] C Ng, D Wadleigh, A Gangopadhyay et al. Paraoxonase-2 is a ubiquitously expressed protein with antioxidant properties and is capable of preventing cell-mediated oxidative modification of low density lipoprotein. J. Biol. Chem. 276 (48); (2001):44444-9.

[13] S Reddy, D Wadleigh, V Grijalva et.al. Human paraoxonase-3 is an HDL-associated enzyme with biological activity similar to paraoxonase-1 protein but is not regulated by oxidized lipids. Arterioscler. Thromb. Vasc. Biol. 21 (4); (2001):542-7.

[14] S Suleyman et.al. Serum arylesterase and paraoxonase activity in patients with chronic hepatitis. World J Gastroenterol.11(46); (2005):7351-4.

[15] Mooradian AD. Asymptomatic hyperthyroidism in older adults: is it a distinct clinical and laboratory entity?. Pub Med. 2008, 25(5):371-80. 
[16] Aldridge WN. Serum esterases. I. Two types of esterase (A and B) hydrolyzing p-nitrophenyl acetate, propionate and butyrate, and a method for their determination. Biochem J 1953; 53:110-7.

[17] Aldridge WN. Serum esterases. II. An enzyme hydrolyzing diethyl p-nitrophenyl phosphate (E600) and its identity with the A-esterase of mammalian sera. Biochem J 1953; 53:117-24.

[18] Sorenson RC, Primo-Parmo SL, Kuo CL, Adkins S, Lockridge O, La Du BN. Reconsideration of the catalytic center and mechanism of mammalian paraoxonase/arylesterase. Proc Natl Acad Sci U S a 1995; 92:7187-91.

[19] Primo-Parmo SL, Sorenson RC, Teiber J, La Du BN. The human serum paraoxonase/arylesterase gene (PON1) is one member of a multigene family. Genomics 1996; 33:498-507.

[20] Mackness MI, Hallam SD, Peard T, Warner S, Walker CH. The separation of sheep and human serum "A"-esterase activity into the lipoprotein fraction by ultracentrifugation. Comp Biochem Physiol B 1985; 82:675-7.

[21] Reddy ST, Wadleigh DJ, Grijalva V, Ng C, Hama S, Gangopadhyay A, Shih DM, Lusis AJ, Navab M, Fogelman AM. Human paraoxonase-3 is an HDL associated enzyme with biological activity similar to paraoxonase-1 protein but is not regulated by oxidized lipids. Arterioscler Thromb Vasc Biol 2001; 21:542-7.

[22] Can M, Mungan AG., Acıkgoz Ş, Yuksel B, Demirtaş S, Tomac N. Effect of montelukast treatment on serum paraoxonase activity in asthmatic children. Turk J Med Sci 2007; 37: 373-6.

[23] Videla LA, Fernandez V. Thyroid calorigenesis and oxidative stress: modification of the respiratory burst activity in polymorphonuclear leukocytes. Braz J Med Biol Res 1994; 27: 2331-42.

[24] Moulakakis KG, Poulakou MV, Paraskevas KI, Dontas I, Vlachos IS, Sokolis DP et al. Hyperthyroidism is associated with increased aortic oxidative DNA damage in a rat model. In Vivo 2007; 21: 1021-6.

[25] Lagrost L. Regulation of cholesteryl ester transfer protein (CETP) activity: review of in vitro and in vivo studies. Biochim Biophys Acta. 1994; 1215:209-36.

[26] Kuusi T, Saarinen P, Nikkila EA. Evidence for the role of hepatic endothelial lipase in the metabolism of plasma high density lipoprotein2 in man. Atherosclerosis. 1980; 36:589-93.

[27] Santamarina-Fojo S, Gonzalez-Navarro H, Freeman L, Wagner E, Nong Z. Hepatic lipase, lipoprotein metabolism, and atherogenesis. Arterioscler Thromb Vasc Biol. 2004; 24:1750-4.

[28] Prieur X, Huby T, Coste H, Schaap FG, Chapman MJ, Rodriguez JC. Thyroid hormone regulates the hypotriglyceridemic gene APOA5. J Biol Chem. 2005; 280:27533-43.

[29] Rensen P, Van Dijk K, Havekes L. Apolipoprotein AV: low concentration, high impact. Arterioscler Thromb Vasc Biol. 2005 ; $25: 2445-7$.

[30] Engler H and Riesen WF. Effect of thyroid function on concentrations of lipoprotein- a. Clin Chem., 1993; 39: 2466-2469.

[31] Kim CS, Kang JG, Lee SJ, et al. Relationship of low-density lipoprotein (LDL) particle size to thyroid function status in Koreans. Clin Endocrinol (Oxf), 2009; 71: 130-136.

[32] Costantini F, Pierdomenico SD et al. Effect of thyroid function on LDL oxidation. Arterioscler Thromb Vasc Biol., 1998; 18 : $732-737$.

[33] Ponsin G, Vialle-Valentin C, Berthezene F. Alterations of high density lipoproteins induced by thyroid hormones in man and rat. Adv Exp Med Biol., 1991; 285: 147-154.

[34] Lagrost L. Regulation of cholesteryl ester transfer protein (CETP) activity: review of in vitro and in vivo studies. Biochim Biophys Acta., 1994; 1215: 209-236.

[35] Kung AW, Pang RW, Lauder I, Lam KS, Janus ED. Changes in serum lipoprotein(a) and lipids during treatment of hyperthyroidism. Clin Chem. 1995; 41:226-31. 